\title{
BMJ Open Heterogeneity in COVID-19 patient volume, characteristics and outcomes across US Department of Veterans Affairs facilities: an observational cohort study
}

Dawn M Bravata (D) , 1,2,3,4,5 Laura J Myers, ${ }^{1,2,4,5}$ Anthony J Perkins, ${ }^{1,6}$ Salomeh Keyhani, ${ }^{1,7,8}$ Ying Zhang, ${ }^{1,9}$ Alan J Zillich, ${ }^{10}$ Andrew Dysangco, ${ }^{3,4}$ Reese Lindsey, ${ }^{3,4}$ Dev Sharmitha, ${ }^{2,3,5,11}$ Jennifer Myers, ${ }^{1,2}$ Charles Austin,, ${ }^{1,2}$ Ali Sexson, ${ }^{1,2}$ Greg Arling ${ }^{1,12}$

To cite: Bravata DM, Myers LJ, Perkins AJ, et al. Heterogeneity in COVID-19 patient volume, characteristics and outcomes across US Department of Veterans Affairs facilities: an observational cohort study. BMJ Open 2021;11:e044646. doi:10.1136/ bmjopen-2020-044646

- Prepublication history and supplemental material for this paper is available online. To view these files, please visit the journal online (http://dx.doi org/10.1136/bmjopen-2020044646).

Received 08 September 2020 Revised 21 December 2020 Accepted 15 February 2021
Check for updates

(C) Author(s) (or their employer(s)) 2021. Re-use permitted under CC BY-NC. No commercial re-use. See rights and permissions. Published by BMJ.

For numbered affiliations see end of article.

Correspondence to Dr. Dawn M Bravata; dawn.bravata2@va.gov

\section{ABSTRACT}

Objective Studies describe COVID-19 patient characteristics and outcomes across populations, but reports of variation across healthcare facilities are lacking. The objectives were to examine differences in COVID-19 patient volume and mortality across facilities, and understand whether facility variation in mortality was due primarily to differences in patient versus facility characteristics.

Design Observational cohort study with multilevel mixed effects logistic regression modelling.

Setting The Veterans Health Administration (VA) is the largest healthcare system in the USA.

Participants Patients with COVID-19.

Main outcome All-cause mortality within 45 days after COVID-19 testing (March-May, follow-up through 16 July 2020).

Results Among 13510 patients with COVID-19, 3942 (29.2\%) were admitted (2266/3942 (57.5\%) ward; $1676 / 3942$ (42.5\%) intensive care unit (ICU)) and 679/3942 (17.2\%) received mechanical ventilation. Marked heterogeneity was observed across facilities in median age (range: $34.3-83.9$ years; facility mean: 64.7, SD 7.2 years); patient volume (range: $1-737$ at 160 facilities; facility median: 48.5, IQR 14-105.5); hospital admissions (range: 1-286 at 133 facilities; facility median: 11, IQR 1-26.5); ICU caseload (range: $1-85$ at 115 facilities; facility median: 4, IQR $0-12$ ); and mechanical ventilation (range: $1-53$ at 90 facilities; facility median: 1, IQR 0-5). Heterogeneity was also observed in facility mortality for all patients with COVID-19 (range: 0\%-29.7\%; facility median: 8.9\%, IQR 2.4\%-13.7\%); inpatients (range: $0 \%-100 \%$; facility median: $18.0 \%$, IQR 5.6\%-28.6\%); ICU patients (range: $0 \%-100 \%$; facility median: $28.6 \%$, IQR 14.3\%-50.0\%); and mechanical ventilator patients (range: $0 \%-100 \%$; facility median: $52.7 \%$, IQR $33.3 \%-80.6 \%$ ). The majority of variation in facility mortality was attributable to differences in patient characteristics (eg, age).

Conclusions Marked heterogeneity in COVID-19 patient volume, characteristics and mortality were observed
Strengths and limitations of this study

Observational cohort study from the largest healthcare system in the USA.

- Focus on the facility level.

- Evaluated care of COVID-19 positive Veteran patients at US Department of Veterans Affairs (VA) facilities; findings should not be generalised to patients cared for in non-VA facilities.

- Described the proportion of patients who were treated in an intensive care unit or received mechanical ventilation, we cannot comment on the appropriateness of such care.

across VA facilities nationwide. Differences in patient characteristics accounted for the majority of explained variation in mortality across sites. Variation in unadjusted COVID-19 mortality across facilities or nations should be considered with caution.

\section{BACKGROUND}

Although studies have described the clinical characteristics of patients with COVID-19, outcome rates, and predictors of adverse outcomes across diverse populations in various countries, these reports have generally focused only on the population level-not the facility level. ${ }^{1-4}$ Reports have described variation in outcomes of patients with COVID-19 across geographic regions and over time, generally reporting higher mortality early in the pandemic. ${ }^{5}$ Studies have also examined the association between patient characteristics and outcomes, for example, consistently identifying an association between older age and increased mortality for patients with COVID19. ${ }^{6}$ Although a few studies have examined facility characteristics that are associated with 
COVID-19 outbreaks within nursing homes, ${ }^{78}$ evaluations of the relative contribution of facility-level characteristics and patient characteristics to patient outcomes have been lacking.

The US Veterans Health Administration (VA) is the largest integrated healthcare system in the USA, providing care for approximately 6.1 million Veteran patients within 170 diverse medical centres. ${ }^{9}{ }^{10}$ VA medical centres are dispersed across the USA and vary in terms of size and services provided. Given that the burden of COVID-19 disease has varied across US communities, we sought to describe the variety in experiences of the 160 VA medical centres that have provided care for patients with COVID19. We had two objectives: (1) to describe observed variation between facilities in terms of overall COVID-19 patient volume, hospital admissions, intensive care unit (ICU) admissions and mechanical ventilation; and (2) to examine the degree to which variance in mortality could be explained by patient-level versus facility-level characteristics by constructing models estimating mortality among patients with COVID-19 based on patient characteristics, care setting (eg, outpatient, inpatient admission and ICU) and facility characteristics.

\section{METHODS}

\section{Cohort construction}

This observational cohort included all Veteran patients (outpatients and inpatients) with a positive COVID-19 test date during the period 1 March 2020-31 May 2020 and followed them for 45 days after the positive test (follow-up period through 16 July 2020). We included Veterans tested in a VA laboratory with COVID-19 positive tests (PCR or antigen testing) and Veterans tested outside of the VA using data from the VA National Surveillance Tool (VA-NST). The VA-NST is a registry that extracts COVID-19 cases in near real time using a combination of laboratory results and natural language processing (NLP) on clinical notes and other documents in the medical record.

In addition, we excluded: patients with a positive antibody test prior to a positive PCR test and non-Veteran patients tested or receiving care at a VA facility (ie, humanitarian cases). We assigned patients to the facility where they obtained their COVID-19 positive test for the description of overall caseload and to the facility where they were admitted for the analyses that included care setting (note: VA facilities span the spectrum from providing primarily outpatient or domiciliary care whereas others provide tertiary care including critical care).

\section{Data sources}

Electronic health record data

Corporate Data Warehouse (CDW) data include information from the Veterans Information Systems and Technology Architecture (VistA). VistA is the electronic medical record system used across the VA system. ${ }^{11}$ CDW data included: inpatient and outpatient data files (eg, clinical encounters with diagnostic and procedure codes) in the 2years prior to the COVID-19 positive test date to identify past medical history, ${ }^{12}$ healthcare utilisation and procedures; vital signs; laboratory data; orders; and medications. The date of death was obtained from multiple sources, including: CDW data; the VA Vital Status File, which uses VA and non-VA sources to identify dates of death for VA beneficiaries; inpatient records that indicated a death disposition; note titles; and chart review. ${ }^{13}$ Facility complexity data were obtained from the VA Office of Productivity, Efficiency and Staffing: facilities are classified into five levels (1a, 1b, 1c, 2 or 3) where level 1a is the most complex and level 3 is the least complex. ${ }^{14}$ Complexity level is based on multiple domains including ICU level, operative complexity, teaching status, research, clinical programme offerings (eg, interventional cardiac catheterisation, transplant, interventional radiology and polytrauma), multicampus status, rurality, community care and mental health services. ICU level is scored from 1 (no ICU) to 5 (a level 1 ICU).

\section{Hospital admission}

VA hospital admission status was identified either after the COVID-19 test date or prior to the COVID-19 test, if the patient was already hospitalised at the time of the testing.

\section{Outcome: 45-day mortality}

Zero-time was the date of the positive COVID-19 test. The primary outcome was all-cause mortality within 45 days of the positive COVID-19 test. We chose the 45-day time frame because our chart review indicated that some patients who died from COVID-19 disease would have been omitted by using a 30-day time horizon.

\section{Chart review validation of electronic health record data}

We conducted chart reviews on samples of patients with COVID-19 to validate the electronic health record data. The chart reviews were conducted iteratively. For example, we validated the COVID-19 positive laboratory test status for 31 patients to ensure that our approach to identifying patients with COVID-19 excluded patients who had non-COVID-19 coronavirus laboratory testing (eg, human coronavirus types 229E, NL63, OC43 and HKU1).

Chart reviews were also conducted to confirm positive test status for non-VA laboratory tests that were included in the VA-NST data. We conducted chart reviews on a sample of 217 charts of patients included in the VA-NST who were not included in VA laboratory data. Chart reviews confirmed that the positive test result in the VA-NST was accurate (ie, a true COVID-19 case). However, the date of positive test was not consistently accurate (because the VA-NST uses NLP and other approaches to identify case status, the first note in the VA medical record about COVID-19 may actually reference testing that was conducted in the non-VA setting days or weeks prior to the date recorded in the VA-NST). 
To ensure that we had complete mortality data, we developed an algorithm validated through chart review. To validate inpatient mortality, we conducted chart reviews on all patients admitted at two large VA hospitals in diverse geographic regions and confirmed that the death information from the various CDW files included mortality status for all inpatients who had died during their hospital stay. To validate mortality in the postdischarge period, we conducted chart review on all patients who were discharged alive from a VA facility but who had neither new laboratory tests nor were not readmitted (both indicators that the patient was alive). To validate mortality in the outpatient setting, we examined 200 charts and 55 facilities searching for mortality status evidence. The mortality algorithm we developed identified 103 of the $111(92.8 \%)$ deaths, which were identified by chart review.

\section{Statistical analysis}

Our analyses were conducted over two main phases. First, we examined unadjusted, observed heterogeneity in patient volume (ie, the number of patients with COVID19) across VA facilities. Specifically, we evaluated total COVID-19 patient volume, number of patients admitted to the hospital, ICU patient volume and number of patients who were mechanically ventilated. Similarly, we examined unadjusted, observed heterogeneity in 45-day mortality across VA facilities.

Second, we sought to examine differences in mortality across facilities after risk adjustment. We began by examining patient-level differences in baseline characteristics among patients with COVID-19 who were admitted versus not admitted to the hospital, and among patients who died versus those who survived 45 days from the COVID-19 positive test date. $\chi^{2}$ tests and Wilcoxon rank-sum tests were used to compare differences in categorical variables. We calculated the Spearman correlation coefficient for the association between baseline characteristics (eg, age) and mortality. Next, we used mixed effects logistic regression modelling to estimate 45-day patient-level mortality across VA facilities with a random effect for facility. We tested four models. Model 1 adjusted only for baseline patient characteristics (eg, age). Model 2 included patient and facility characteristics (to examine relative contribution of the facility characteristics). Model 3 added where the setting where the patient received care (eg, inpatient ward vs ICU) to model 1 . Model 4 added facility characteristics to model 3. Finally, we examined the variance in facility mortality across models to explore the degree to which differences in mortality across facilities was associated with patient-level versus facility-level characteristics.

We conducted sensitivity analyses by restricting the cohort only to Veteran patients with a positive COVID-19 test at a VA laboratory (excluding patients who were only identified in the VA-NST because of our inability to confirm the dates of the COVID-19 tests) and also excluded patients residing in VA Community Living Centers (CLC) at the time of the COVID-19 positive test (because some COVID-19 CLC patients were transferred to a different VA for admission, and other patients were retained within the same facility but moved from the CLC unit to the acute care part of the hospital). We also used proportional hazard modelling mortality across the same 45-day time frame as in the main analysis as a confirmatory analysis. All analyses were performed using SAS Enterprise Guide V.7.11.

\section{Data availability}

These data must remain on VA servers. No data are available. In the interest of data transparency, investigators interested in working with the data are encouraged to contact the corresponding author.

\section{Ethics approval}

A waiver of informed consent and Health Insurance Portability and Accountability Act (HIPAA) authorisation were granted for the collection of medical record data.

\section{Patient and public involvement}

No patients or members of the public were involved in the design or conduct of this study. Results will be distributed to VA leadership at the national and regional levels.

\section{RESULTS}

Among 13510 COVID-19 positive Veterans: 3942 (29.2\%) were admitted to a VA hospital, either to an inpatient ward $(2266 / 3942(57.5 \%))$ or to ICU $(1676 / 3942$ $(42.5 \%))$; and $679 / 3942(17.2 \%)$ received mechanical ventilation. A total of 493/13 510 (3.6\%) patients were hospitalised at the time of their COVID-19 testing. The median time from COVID-19 test to admission (among patients for whom the test was performed before or on the day of admission) was 0 days (IQR $0-1$ ). A total of 276/13 $510(2.0 \%)$ patients (at 30 VA facilities) obtained their COVID-19 positive test at one VA facility but were admitted to a different hospital.

\section{Heterogeneity in caseload across VA facilities}

Substantial heterogeneity in COVID-19 caseload was observed (figure 1). COVID-19 patient volume ranged from 1 to 737 across 160 VA facilities (facility median: 48.5, IQR 14-105.5). Hospital admissions ranged from 1 to 286 (facility median: 11, IQR 1-26.5) with at least one patient being admitted at 133 facilities. ICU caseload ranged from 0 to 85 across facilities (facility median: 4, IQR $0-12$ ) with at least one patient being admitted to the ICU at 115 facilities. Among the 133 facilities with at least one COVID-19 hospital admission, the proportion of patients within a facility who were cared for in the ICU ranged from $0 \%$ to $77.8 \%$. The number of patients requiring mechanical ventilation ranged from 0 to 53 across facilities (facility median: 1, IQR 0-5) with patients receiving mechanical ventilation at 90 facilities. Among the 115 facilities with at least one COVID-19 ICU admission, the proportion of patients within a facility who received mechanical ventilation ranged from $0 \%$ to $55.6 \%$. 
Panel A. Total COVID-19 Patient Volume by Facility

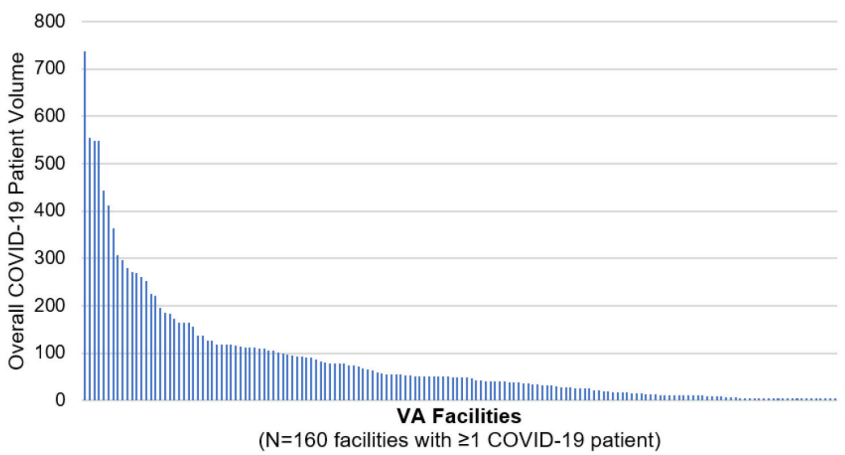

Panel B. COVID-19 Hospital Admissions by Facility

350

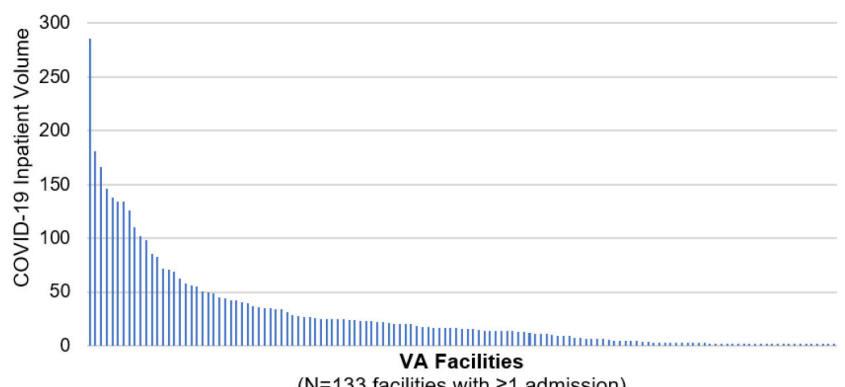

Panel C. COVID-19 Intensive Care Unit Patients by Facility

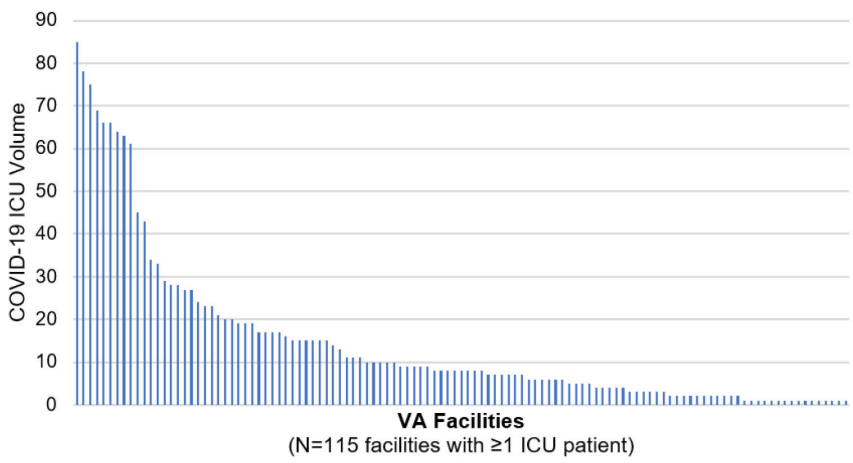

Panel D. COVID-19 Mechanical Ventilator Patients by Facility

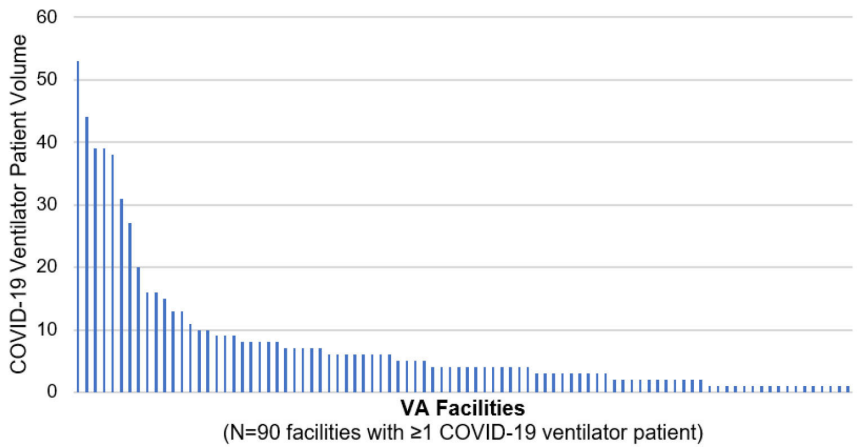

Figure 1 The figure displays the total number of COVID-19 Veteran patients across US Veterans Health Administration facilities (panel A; $n=160$ facilities had at least one COVID-19 positive patient), the number of hospital admissions (panel B; $n=133$ facilities had at least one COVID-19 hospital admission), the number of patients cared for in an intensive care unit (ICU) per facility (panel C; $n=115$ facilities had at least one ICU admission); and the number of patients with mechanical ventilation (panel $\mathrm{D} ; \mathrm{n}=90$ facilities had at least one patient on a mechanical ventilator).

\section{Heterogeneity in case-mix across VA facilities}

Heterogeneity across facilities in factors that have been associated with poor COVID-19 outcomes was also observed (online supplemental figure A). For example, the median age of patients with COVID-19 by facility varied from 34.3 to 83.9 years (mean across facilities: $64.7 \pm \mathrm{SD}$, 7.2 years). The facility median age was $<50$ years at $5 / 160$ $(3.1 \%)$ facilities, $\geq 50$ but $<60$ years at $24 / 160(15.0 \%)$ facilities, $\geq 60$ but $<70$ years at $94 / 160(58.8 \%)$ facilities and $\geq 70$ years for $37 / 160(23.1 \%)$ facilities. In unadjusted analyses, older patients were more likely to be admitted than younger patients (table 1). For example, only $14.7 \%$ $(520 / 3549)$ of patients with COVID-19 who were $<55$ years old were admitted to the hospital, but $35.4 \%$ (504/1422) of patients $\geq 85$ years old were admitted $(\mathrm{p}<0.001)$. In unadjusted analyses, older patients were also more like to die than younger patients (table 1): $1.0 \%$ (34/3549) of patients with COVID- $19<55$ years old died within 45 days of the COVID-19 positive laboratory test compared with $33.8 \%$ (481/1422) mortality among patients $\geq 85$ years old $(p<0.001$; online supplemental figure B). Several patient characteristics were more common among patients with COVID-19 who were admitted to the hospital including: black race; male gender; history of hypertension, diabetes, chronic obstructive pulmonary disease (COPD), chronic kidney disease (CKD), congestive heart failure (CHF), atrial fibrillation, cancer and myocardial infarction (MI); current smoking; low body mass index $\left(<25 \mathrm{~kg} / \mathrm{m}^{2}\right)$; and residence in a long-term care facility (table 1 ).

\section{Heterogeneity in observed mortality across VA facilities}

The unadjusted, observed facility 45-day all-cause mortality rate for all patients with COVID-19 ranged from $0 \%$ to $29.7 \%$ (facility median: $8.9 \%$, IQR $2.4 \%-13.7 \%$ ). Among facilities with at least 10 patients with COVID-19, the mean facility mortality rate was $10.1 \%$ (SD of $6.3 \%$ ). The facility mortality rate for patients with COVID-19 who were admitted to the hospital ranged from $0 \%$ to $100 \%$ (facility median: 18.0\%, IQR 5.6\%-28.6\%). Among facilities with at least 10 patients with COVID-19 who were admitted to the hospital, the mean facility mortality rate among admitted patients was $20.7 \%$ (SD of $10.7 \%$ ). In contrast, the facility mortality for patients with COVID-19 who were not admitted ranged from $0 \%$ to $32.1 \%$ (facility median: $3.6 \%$, IQR $0 \%-8.3 \%$ ). The facility mortality for COVID-19 ICU patients ranged from $0 \%$ to $100 \%$ (facility median: $28.6 \%$, IQR $14.3 \%-50.0 \%$ ). Among facilities with at least 10 patients with COVID-19 in the ICU, the mean facility mortality rate for ICU patients was $32.7 \%$ (SD of 14.3\%). The facility mortality for patients with COVID-19 requiring mechanical ventilation ranged from $0 \%$ to $100 \%$ (facility median: $52.7 \%$, IQR $33.3 \%-$ $80.6 \%)$. Figure 2 displays the unadjusted mortality rates with patient volume for each facility. In general, facilities 
Table 1 Patient characteristics among COVID-19 positive Veteran patients

\begin{tabular}{|c|c|c|c|c|c|c|c|}
\hline \multirow[b]{3}{*}{ Baseline characteristics } & $\begin{array}{l}\text { Overall } \\
(n=13510)\end{array}$ & $\begin{array}{l}\text { Not admitted } \\
(\mathrm{n}=9568)\end{array}$ & $\begin{array}{l}\text { Admitted } \\
(\mathrm{n}=3942)\end{array}$ & \multirow[b]{3}{*}{$P$ value } & $\begin{array}{l}\text { Alive } \\
(\mathrm{n}=12043)\end{array}$ & $\begin{array}{l}\text { Died within } 45 \\
\text { days }(n=1467)\end{array}$ & \multirow[b]{3}{*}{$P$ value } \\
\hline & Column & Row & Row & & Row & Row & \\
\hline & N (\%) & N (\%) & N (\%) & & $\mathbf{N}(\%)$ & N (\%) & \\
\hline Age (years) & & & & $<0.001$ & & & $<0.001$ \\
\hline$<55$ & 3549 (26.3) & 3029 (85.4) & $520(14.6)$ & & $3515(99.0)$ & $34(1.0)$ & \\
\hline $55-64$ & $2872(21.3)$ & 2076 (72.3) & $796(27.7)$ & & $2750(95.8)$ & $122(4.2)$ & \\
\hline $75-84$ & $1853(13.7)$ & $1131(61.0)$ & $722(39.0)$ & & $1499(80.9)$ & $354(19.1)$ & \\
\hline$\geq 85$ & $1422(10.5)$ & $918(64.6)$ & $504(35.4)$ & & $941(66.2)$ & $481(33.8)$ & \\
\hline Race & & & & $<0.001$ & & & $<0.001$ \\
\hline White & $6906(51.1)$ & $5128(74.3)$ & $1778(25.7)$ & & $6065(87.8)$ & $841(12.2)$ & \\
\hline $\begin{array}{l}\text { Native Hawaiian or other } \\
\text { Pacific Islander }\end{array}$ & $99(0.7)$ & $81(81.8)$ & $18(18.2)$ & & $90(90.9)$ & $9(9.1)$ & \\
\hline Ethnicity & & & & 0.089 & & & $<0.001$ \\
\hline Not Hispanic & $12262(90.8)$ & 8658 (70.6) & $3604(29.4)$ & & $10889(88.8)$ & $1373(11.2)$ & \\
\hline Hispanic & $1248(9.2)$ & $910(72.9)$ & $338(27.1)$ & & $1154(92.5)$ & $94(7.5)$ & \\
\hline Gender & & & & $<0.001$ & & & $<0.001$ \\
\hline Female & $1239(9.2)$ & $1046(84.4)$ & $193(15.6)$ & & $1205(97.3)$ & $34(2.7)$ & \\
\hline Male & $12270(90.8)$ & $8529(69.4)$ & $3749(30.6)$ & & $10837(88.3)$ & $1433(11.7)$ & \\
\hline Yes & $5176(38.3)$ & 3206 (61.9) & $1970(38.1)$ & & $4453(86.0)$ & $723(14.0)$ & \\
\hline $\begin{array}{l}\text { Chronic obstructive } \\
\text { pulmonary disease }\end{array}$ & & & & $<0.001$ & & & $<0.001$ \\
\hline No & $10322(76.4)$ & 7589 (73.5) & $2733(26.5)$ & & $9301(90.1)$ & $1021(9.9)$ & \\
\hline Yes & $3188(23.6)$ & $1979(62.1)$ & 1209 (37.9) & & $2742(86.0)$ & $446(14.0)$ & \\
\hline Chronic kidney disease & & & & $<0.001$ & & & $<0.001$ \\
\hline No & $11047(81.8)$ & $8289(75.0)$ & $2758(25.0)$ & & $10081(91.3)$ & $966(8.7)$ & \\
\hline Yes & $2463(18.2)$ & 1279 (51.9) & $1184(48.1)$ & & $1962(79.7)$ & $501(20.3)$ & \\
\hline Congestive heart failure & & & & $<0.001$ & & & $<0.001$ \\
\hline No & $11518(85.3)$ & 8516 (73.9) & $3002(26.1)$ & & $10458(90.8)$ & $1060(9.2)$ & \\
\hline Yes & $1992(14.7)$ & $1052(52.8)$ & $940(47.2)$ & & $1585(79.6)$ & $407(20.4)$ & \\
\hline Atrial fibrillation & & & & $<0.001$ & & & $<0.001$ \\
\hline No & $11877(87.9)$ & 8651 (72.8) & $3226(27.2)$ & & $10739(90.4)$ & $1138(9.6)$ & \\
\hline Yes & $1633(12.1)$ & $917(56.2)$ & $716(43.8)$ & & $1304(79.8)$ & $329(20.2)$ & \\
\hline Cancer & & & & $<0.001$ & & & $<0.001$ \\
\hline No & $12484(92.4)$ & $8996(72.1)$ & $3488(27.9)$ & & $11194(89.7)$ & $1290(10.3)$ & \\
\hline Yes & $1026(7.6)$ & $572(55.8)$ & $454(44.2)$ & & $849(82.8)$ & $177(17.2)$ & \\
\hline Myocardial infarction & & & & $<0.001$ & & & $<0.001$ \\
\hline
\end{tabular}


Table 1 Continued

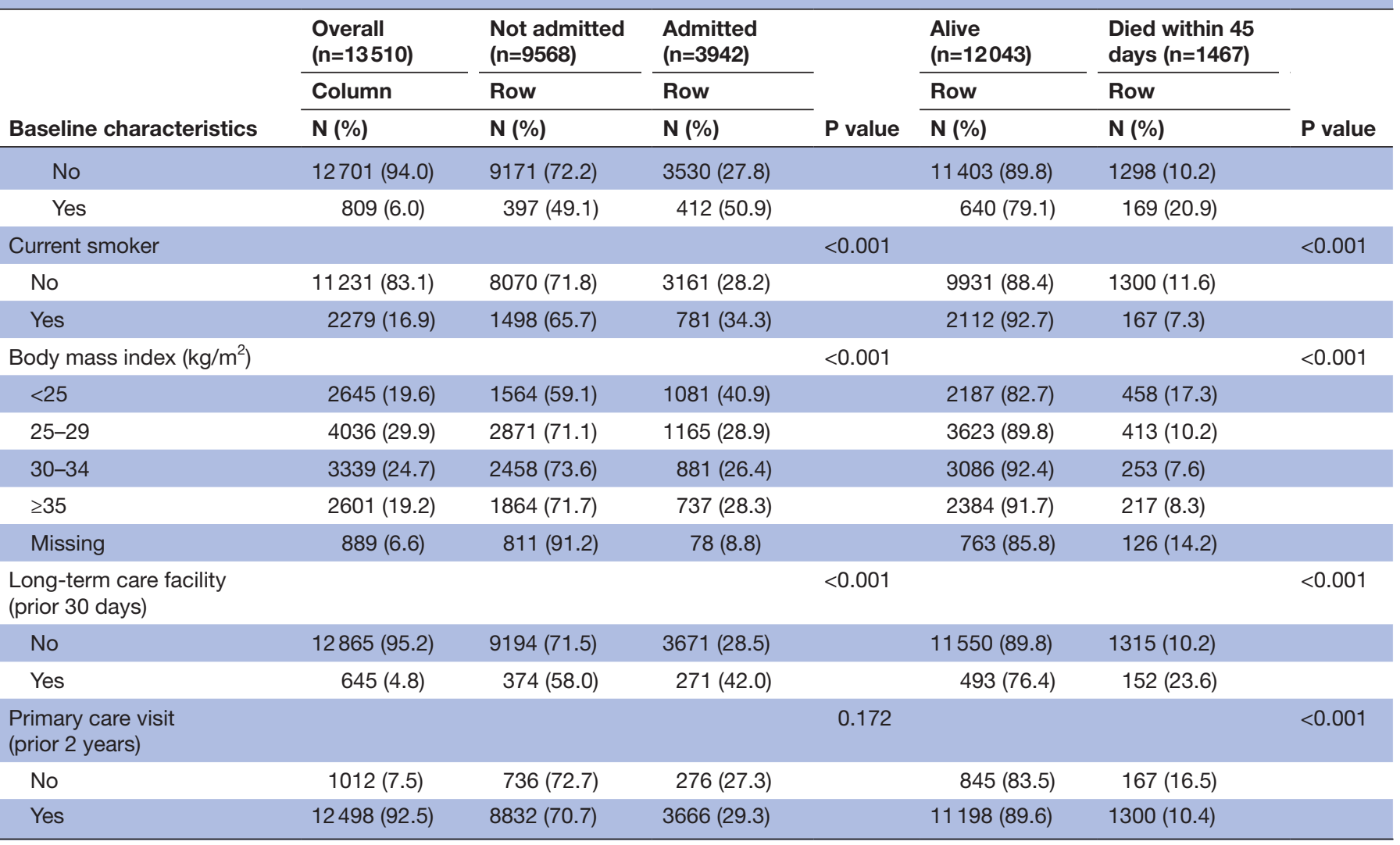

Panel A. Mortality Among All COVID-19 Patients by Facility

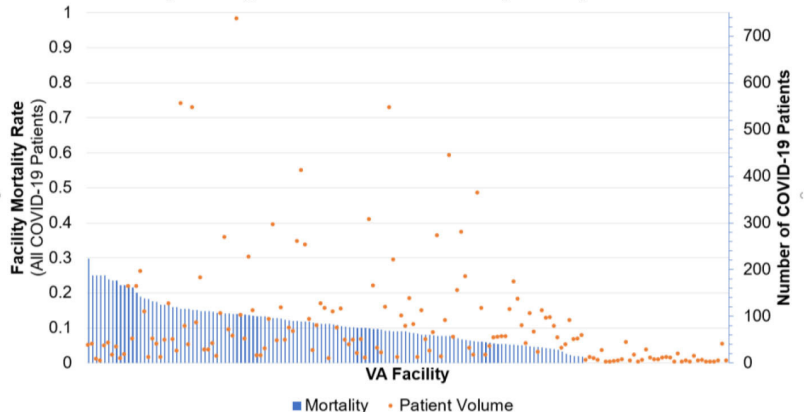

Panel B. Mortality Among Admitted COVID-19 Patients by Facility

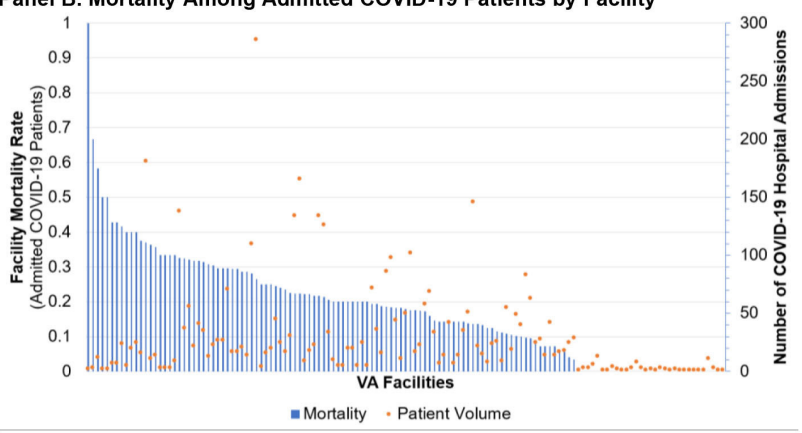

Panel C. Mortality Among COVID-19 Intensive Care Unit (ICU) Patients by Facility

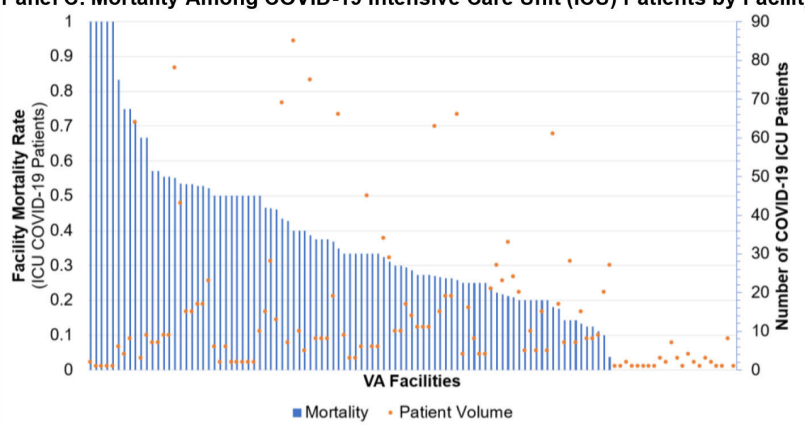

Panel D. Mortality Among COVID-19 Mechanical Ventilator Patients by Facility

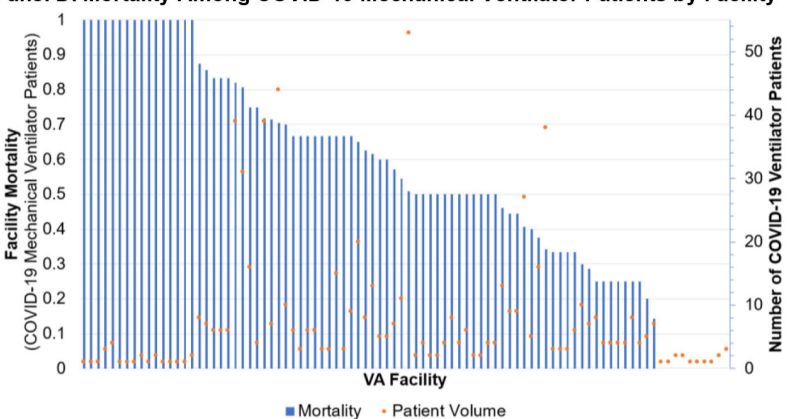

Figure 2 The figure displays the differences in the facility all-cause, 45-day mortality rates for COVID-19 patients: panel A includes 160 facilities with at least one patient with COVID-19; panel B includes 133 facilities with at least one COVID-19 inpatient cared for on a general ward or critical care unit; panel C includes 115 facilities with at least one COVID-10 ICU patient; and panel $\mathrm{D}$ includes 90 facilities with at least one patient with COVID-19 who received mechanical ventilation. 
with extreme mortality rates (eg, $0 \%$ or $100 \%$ mechanical ventilator mortality; figure 2 , panel $D$ ) had very few patients.

\section{Risk-adjusted mortality across VA facilities}

The patient characteristics that were independently associated with increased mortality included: increasing age, Asian race, diabetes, $\mathrm{CKD}, \mathrm{MI}, \mathrm{CHF}$ and residence in a long-term care facility (table 2, model 1). Patients who were admitted to the hospital, cared for in an ICU and those who received mechanical ventilation all had an higher odds of mortality compared with patients who were cared for entirely in the outpatient setting (table 2). The patient characteristics that were independently associated with decreased mortality included: female gender, higher body mass index $\left(\geq 25 \mathrm{~kg} / \mathrm{m}^{2}\right)$, being seen by a primary care provider within prior 2 years and current smoking status (table 2).

The patient admission category (models 3 and 4) demonstrated a robust and statistically significant association with mortality: no admission (reference category), hospital admission without ICU or mechanical ventilation (OR1.25 (95\% CI 1.04 to 1.500)), ICU without mechanical ventilation (OR 3.23 (95\% CI 2.64 to 3.96)) and mechanical ventilation (OR 27.33 (95\% CI 22.11 to 33.77)). When patient admission category was included, two comorbidities (diabetes and CHF) from model 1 were no longer significantly associated with mortality (table 2).

The facility characteristics that were associated with mortality in bivariate analyses included: mean age at the facility, proportion of patients admitted to the ICU, proportion receiving mechanical ventilation, overall caseload and facility complexity (online supplemental figures $\mathrm{B}$ and $\mathrm{C}$ ). When facility characteristics were included in the multivariable models (models 2 and 4), the patient level estimates were similar to those obtained in models 1 and 3 . The only facility characteristics that was independently associated with COVID-19 mortality after risk adjustment for patient characteristics was an increasing proportion of patients with mechanical ventilation (table 2, model 2). The total number of patients with COVID-19 was not associated with mortality (table 2, models 2 and 4). Similarly, facility complexity and rural location were also not independently associated with mortality (table 2, models 2 and 4 ). In sensitivity analyses, the mixed effects logistic regression results were similar when excluding CLC patients and registry-only patients (online supplemental table A). The proportional hazard model results were also similar to the primary analysis. The C-statistic was 0.796 for model 1, 0.866 for model 2, 0.868 for model 3 and 0.799 for model 4 (table 3 ).

\section{Variation in mortality across VA facilities}

Of the four multivariable models, model 2 with patient characteristics (excluding patient admission status) and facility characteristics reduced the variation most across facilities from 0.177 to 0.061 (table 3). However, the majority of the variance in mortality was accounted for by patient factors only (model 1): 0.177 to 0.074 is a $58.2 \%$ reduction in variance. In contrast, the addition of facility characteristics to the multivariable modelling only reduced the variance in mortality from 0.074 (model 1) to 0.061 (model 2), which is a $7.3 \%$ reduction in variance. Including the patient-level variable for admission status to the model (model 3) increased the C-statistic from 0.799 to 0.868 ; however, the variation across facilities also increased from 0.061 to $0.136 .{ }^{15}$

\section{DISCUSSION}

Although studies have examined differences in COVID-19 prevalence $^{16}$ or outcomes ${ }^{17}$ across geographic regions, few reports explicitly describe variation across facilities. ${ }^{1}$ Substantial heterogeneity in caseload was observed across facilities within the VA system. We found that although observed mortality varied dramatically across facilities, heterogeneity in facility mortality rates was likely primarily due to differences in patient characteristics (eg, age, comorbidities and clinical disease severity) rather than differences in facility characteristics (eg, ICU level). This finding is reassuring from a public health perspective because it indicates that outcomes for patients with COVID-19 were similar across the full spectrum of hospitals from small, rural facilities without teaching services or research enterprises to large, academic centres.

The results are in alignment with the literature that has described the association between COVID-19 outcomes and patient factors (age in particular) ${ }^{18} 19$ Across all four of the multivariable models, the association between age and mortality among patients with COVID-19 was monotonic and robust. Compared with younger patients $(<55$ years old), patients $\geq 85$ years old had $\mathrm{a} \geq 38$-fold increased odds of death within 45 days of the positive COVID-19 laboratory test. These results support public health initiatives that seek to protect the elderly from exposure to COVID-19 given their very high risk of mortality.

The population that was the focus of this study, US Veterans, with a median age of 64.7 years was older than cohorts reported from China especially those evaluated early in the pandemic (median age was 46.2 years among 43 studies included in a meta-analysis) ${ }^{20}$ However, when focusing on populations of patients with COVID-19 who were admitted to a hospital, this US Veteran population with COVID-19 was similar to a hospitalised population from England where the median age was 72 years and $36.1 \%$ were $\geq 80$ years of age. ${ }^{21}$ A study from Italy of patients hospitalised with COVID-19 reported a mean age of 67 years. Differences in age across populations may be a consequence of variation in testing practices. If hospitalised patients are more likely to be tested, and if older patients are more likely to be hospitalised, then regions with lower outpatient testing rates are expected to have overall older aged COVID-19 patient cohorts.

Our findings of variation of caseload across facilities is analogous to reports of geographic heterogeneity in disease prevalence. ${ }^{22}$ For example, a serological survey 
Table 2 Mixed effects logistic regression modelling 45-day mortality among patients with COVID-19 Patients with COVID-19 ( $n=13510$ patients at $n=160$ facilities)

\begin{tabular}{|c|c|c|c|c|c|c|c|c|}
\hline \multirow{3}{*}{ Characteristics } & & & & & \multirow{2}{*}{\multicolumn{2}{|c|}{$\begin{array}{l}\text { Patient characteristics and } \\
\text { admission category }\end{array}$}} & & \\
\hline & \multicolumn{2}{|c|}{ Patient characteristics only } & \multicolumn{2}{|l|}{$\begin{array}{l}\text { Patient and facility } \\
\text { characteristics }\end{array}$} & & & \multicolumn{2}{|l|}{$\begin{array}{l}\text { Patient and facility } \\
\text { characteristics, and } \\
\text { admission category }\end{array}$} \\
\hline & \multicolumn{2}{|l|}{ Model 1} & \multicolumn{2}{|l|}{ Model 2} & \multicolumn{2}{|l|}{ Model 3} & \multicolumn{2}{|l|}{ Model 4} \\
\hline \multicolumn{9}{|l|}{ Patient-level characteristics } \\
\hline Age (years) & & $<0.001$ & & $<0.001$ & & $<0.001$ & & $<0.001$ \\
\hline $55-64$ & 3.98 (2.69 to 5.88$)$ & & 3.95 (2.67 to 5.84$)$ & & 3.33 (2.21 to 5.00$)$ & & 3.29 (2.19 to 4.95$)$ & \\
\hline $65-74$ & 11.13 (7.71 to 16.07$)$ & & 11.03 (7.63 to 15.94$)$ & & $9.38(6.41$ to 13.73$)$ & & 9.25 (6.32 to 13.55$)$ & \\
\hline $75-84$ & 17.80 (12.20 to 25.97$)$ & & $17.56(12.02$ to 25.65$)$ & & $17.12(11.55$ to 25.39$)$ & & 16.86 (11.36 to 25.03 ) & \\
\hline$\geq 85$ & 38.73 (26.46 to 56.68$)$ & & 38.23 (26.08 to 56.04$)$ & & 43.89 (29.50 to 65.32$)$ & & 43.06 (28.91 to 64.15$)$ & \\
\hline Race & & 0.017 & & 0.02 & & 0.099 & & 0.092 \\
\hline Black & 1.14 (0.99 to 1.31$)$ & & 1.14 (0.99 to 1.31$)$ & & 0.91 (0.78 to 1.07 ) & & 0.93 (0.79 to 1.09$)$ & \\
\hline $\begin{array}{l}\text { Native Hawaiian or other } \\
\text { Pacific Islander }\end{array}$ & 1.50 (0.71 to 3.15$)$ & & 1.58 (0.75 to 3.32$)$ & & 1.45 (0.63 to 3.32$)$ & & 1.52 (0.66 to 3.48$)$ & \\
\hline Unknown & 0.84 (0.62 to 1.15$)$ & & 0.84 (0.62 to 1.15$)$ & & 0.79 (0.57 to 1.10$)$ & & 0.78 (0.56 to 1.08$)$ & \\
\hline White & 1 & & & & 1 & & 1 & \\
\hline Hispanic & 1.05 (0.82 to 1.35 ) & 0.676 & 1.05 (0.82 to 1.35$)$ & 0.691 & 0.96 (0.73 to 1.26$)$ & 0.767 & 0.97 (0.73 to 1.27$)$ & 0.802 \\
\hline Female & 0.57 (0.39 to 0.82$)$ & 0.002 & 0.57 (0.40 to 0.83$)$ & 0.004 & 0.67 (0.46 to 0.99$)$ & 0.045 & 0.67 (0.46 to 0.99$)$ & 0.044 \\
\hline \multicolumn{9}{|l|}{ Medical history } \\
\hline Hypertension & $0.99(0.84$ to 1.17$)$ & 0.932 & $0.99(0.84$ to 1.17$)$ & 0.903 & $0.93(0.77$ to 1.11$)$ & 0.422 & 0.93 (0.78 to 1.12$)$ & 0.443 \\
\hline Diabetes & 1.22 (1.07 to 1.38$)$ & 0.003 & 1.21 (1.06 to 1.38$)$ & 0.004 & 1.13 (0.98 to 1.30$)$ & 0.102 & $1.12(0.97$ to 1.29$)$ & 0.112 \\
\hline Body mass index $\left(\mathrm{kg} / \mathrm{m}^{2}\right)$ & & $<0.001$ & & $<0.001$ & & 0.001 & & 0.001 \\
\hline$<25$ & 1 & & 1 & & 1 & & 1 & \\
\hline $25-29$ & 0.82 (0.70 to 0.95 ) & & 0.82 (0.70 to 0.96$)$ & & 0.80 (0.67 to 0.95$)$ & & 0.80 (0.68 to 0.95$)$ & \\
\hline $30-34$ & 0.77 (0.64 to 0.92$)$ & & 0.78 (0.65 to 0.93$)$ & & 0.75 (0.62 to 0.92$)$ & & 0.75 (0.62 to 0.92$)$ & \\
\hline$\geq 35$ & 1.15 (0.94 to 1.40$)$ & & $1.16(0.95$ to 1.41$)$ & & 1.04 (0.84 to 1.30$)$ & & 1.04 (0.84 to 1.30$)$ & \\
\hline Missing & 0.94 (0.72 to 1.24$)$ & & 0.96 (0.72 to 1.26$)$ & & 1.18 (0.88 to 1.58$)$ & & 1.17 (0.88 to 1.57$)$ & \\
\hline $\begin{array}{l}\text { Primary care within prior } \\
2 \text { years }\end{array}$ & 0.67 (0.53 to 0.85$)$ & 0.001 & 0.68 (0.54 to 0.86$)$ & 0.001 & 0.77 (0.60 to 0.99$)$ & 0.043 & 0.77 (0.60 to 0.99$)$ & 0.045 \\
\hline $\begin{array}{l}\text { Community Living Centre: prior } \\
30 \text { days }\end{array}$ & $1.41(1.12$ to 1.76$)$ & 0.003 & 1.41 (1.03 to 1.95$)$ & 0.035 & 1.77 (1.39 to 2.25$)$ & $<0.001$ & 1.74 (1.37 to 2.23$)$ & $<0.001$ \\
\hline Current smoker & 0.81 (0.67 to 0.97 ) & 0.025 & 1.61 (1.16 to 2.22$)$ & 0.005 & 0.75 (0.62 to 0.93 ) & 0.007 & 0.76 (0.62 to 0.93 ) & 0.007 \\
\hline Patient admission category & & & & & & $<0.001$ & & $<0.001$ \\
\hline No admission (reference) & & & & & 1 & & 1 & \\
\hline $\begin{array}{l}\text { Hospital admission (not ICU, } \\
\text { not mechanical ventilation) }\end{array}$ & & & & & 1.25 (1.04 to 1.50$)$ & & 1.29 (1.07 to 1.56$)$ & \\
\hline $\begin{array}{l}\text { ICU (not mechanical } \\
\text { ventilation) }\end{array}$ & & & & & 3.24 (2.65 to 3.96 ) & & 3.40 (2.77 to 4.18$)$ & \\
\hline Mechanical ventilation & & & & & 27.37 (22.14 to 33.83 ) & & 29.12 (23.42 to 36.21$)$ & \\
\hline
\end{tabular}


Table 2 Continued

\begin{tabular}{|c|c|c|c|c|c|c|c|}
\hline \multirow[b]{3}{*}{ Characteristics } & \multicolumn{7}{|c|}{ Patients with COVID-19 ( $n=13510$ patients at $n=160$ facilities) } \\
\hline & Patient characteristics only & \multicolumn{2}{|l|}{$\begin{array}{l}\text { Patient and facility } \\
\text { characteristics }\end{array}$} & \multicolumn{2}{|c|}{$\begin{array}{l}\text { Patient characteristics and } \\
\text { admission category }\end{array}$} & \multicolumn{2}{|l|}{$\begin{array}{l}\text { Patient and facility } \\
\text { characteristics, and } \\
\text { admission category }\end{array}$} \\
\hline & $\begin{array}{l}\text { OR } \\
(95 \% \mathrm{Cl})\end{array}$ & $\begin{array}{l}\text { OR } \\
(95 \% \mathrm{Cl})\end{array}$ & $\begin{array}{l}P \\
\text { value }\end{array}$ & $\begin{array}{l}\text { OR } \\
(95 \% \mathrm{Cl})\end{array}$ & $\begin{array}{l}P \\
\text { value }\end{array}$ & $\begin{array}{l}\text { OR } \\
(95 \% \mathrm{Cl})\end{array}$ & $\begin{array}{l}P \\
\text { value }\end{array}$ \\
\hline $\begin{array}{l}\text { Number of patients with } \\
\text { COVID-19 }\end{array}$ & & & 0.131 & & & & 0.174 \\
\hline $20-49$ & & $1.40(1.06$ to 1.84$)$ & & & & 1.27 (0.91 to 1.77$)$ & \\
\hline $50-99$ & & $1.06(0.84$ to 1.34$)$ & & & & $0.98(0.74$ to 1.30$)$ & \\
\hline$\geq 100$ (reference) & & 1 & & & & 1 & \\
\hline Mean patient age & & $1.02(1.00$ to 1.04$)$ & 0.066 & & & 1.02 (0.99 to 1.04$)$ & 0.138 \\
\hline $20.0+$ & & 0.95 (0.66 to 1.36$)$ & & & & 0.86 (0.56 to 1.32$)$ & \\
\hline $\begin{array}{l}\text { Percentage of patients in ICU } \\
\text { with mechanical ventilation }\end{array}$ & & & 0.706 & & & & 0.117 \\
\hline 0 (reference) & & 1 & & & & 1 & \\
\hline $0.01-9.99$ & & $1.10(0.75$ to 1.60$)$ & & & & 1.07 (0.69 to 1.66$)$ & \\
\hline$\geq 10.0$ & & 1.02 (0.69 to 1.48$)$ & & & & $0.82(0.53$ to 1.29$)$ & \\
\hline $\begin{array}{l}\text { Percent patients with } \\
\text { mechanical ventilation }\end{array}$ & & & 0.017 & & & & 0.156 \\
\hline 0 (reference) & & 1 & & & & 1 & \\
\hline $0.01-4.99$ & & 1.41 (1.03 to 1.95$)$ & & & & 1.03 (0.70 to 1.49$)$ & \\
\hline
\end{tabular}

ICU, intensive care unit.

from Spain reported substantial geographical variation, with higher prevalence near Madrid $(>10 \%)$ and lower prevalence in coastal areas $(<3 \%) .{ }^{23}$ A study from the USA reported higher COVID-19 mortality in rural versus urban communities; however, that study was limited to countylevel (not patient level) data. ${ }^{24}$ In contrast, our results indicated that facility rurality was not independently associated with COVID-19 patient mortality. The current study

Table 3 Random variation across facility 45-day mortality rates

\begin{tabular}{|c|c|c|c|}
\hline \multirow[b]{2}{*}{ Model } & \multicolumn{2}{|c|}{$\begin{array}{l}\text { All patients ( } n=13510 \\
\text { patients at } n=160 \text { facilities) }\end{array}$} & \multirow{2}{*}{$\begin{array}{l}\text { VA laboratory patients* (excluded registry and } \\
\text { CLC patients) ( } n=7535 \text { patients at } n=149 \text { facilities) } \\
\text { Variance (SE) }\end{array}$} \\
\hline & C-statistic & Variance (SE) & \\
\hline Model 1: patient characteristics only & 0.796 & $0.074(0.028)$ & $0.081(0.037)$ \\
\hline Model 2: patient characteristics+facility characteristics & 0.799 & $0.061(0.026)$ & $0.047(0.031)$ \\
\hline Model 3: patient characteristics+admission category† & 0.866 & $0.160(0.046)$ & $0.190(0.067)$ \\
\hline
\end{tabular}

*This sensitivity analysis included Veterans identified in the VA laboratory data only; Veterans identified only in the VA-NST registry and those who were Community Living Centre (CLC) residents in the 30 days prior to the COVID-19 positive test were excluded.

†Admission category refers to the setting where patients with COVID-19 received care: outpatient, admission to an inpatient ward, intensive care unit and mechanical ventilator.

VA-NST, VA National Surveillance Tool. 
adds to the existing literature by describing heterogeneity at the facility level within a national healthcare system.

Our finding that current smokers with COVID-19 were more likely to be admitted than non-smokers but that in multivariable modelling current smoking was associated with a lower risk of mortality is consistent with reports from cohorts in England, ${ }^{18}$ China $^{25}$ and Italy, ${ }^{26}$ as well as an ecological study of 38 European countries. ${ }^{27}$ Although studies have suggested that nicotine exposure is related to ACE2 expression, ${ }^{28}$ and diseases associated with smoking such as COPD increase the risk of severe COVID-19 infection, ${ }^{29}$ the role of nicotine and smoking in COVID-19 disease remains a topic of active investigation.

The results suggest that reported variation in unadjusted mortality rates should be considered with caution and must be evaluated within the context of sample size and patient characteristics. ${ }^{1}$ For example, the overall in-hospital mortality rate of $18.2 \%$ among VA hospitals is somewhat higher than reports from the Kaiser Permanente Northern California system of $15.6 \%$, a healthcare system that cares for a younger cohort (mean age 61.0 years compared with 63.5 years in the VA) ${ }^{30}$ Future studies of COVID-19 outcomes should include risk adjustment for relevant patient characteristics and should report C-statistics or other measures of model performance.

\section{Limitations}

Several potential limitations of this national cohort study merit description. First, we evaluated care of COVID-19 positive Veteran patients at VA facilities; findings cannot be generalised to Veterans cared for in community (non-VA) facilities. ${ }^{31}$ Second, this study did not evaluate outcomes for non-COVID-19 patients at VA hospitals; therefore, we did not evaluate the potential effects of COVID-19 on non-COVID-19 hospital operations. ${ }^{32}$ Third, although a methodological strength of the study was the chart review validation of the administrative data, the outpatient mortality rates may still be underestimates because of delays in updating national VA death indices. Fourth, we do not have non-VA healthcare utilisation; therefore, patients may have received COVID-19 testing within the VA but were subsequently hospitalised at a non-VA community hospital. Fifth, we described the proportion of patients who were treated in an ICU or received mechanical ventilation; we cannot comment on the appropriateness of such care. Sixth, we examined all-cause mortality in the 45-day period after COVID-19 testing. Although it is likely that death among patients with COVID-19 was attributable to COVID-19 disease, some patients may have died from other causes (eg, preexisting illness). Seventh, US Veterans are predominantly male, which may limit generalisability of findings to nonVeteran populations. Finally, although many key patients and facility characteristics were included in the analyses, there are many potential factors that may contribute to mortality among patients with COVID-19 including patient characteristics (eg, occupation) and facility characteristics (eg, environmental factors) that were not included in the multivariable modelling.

\section{Conclusions}

In this national cohort of 13510 US Veterans with a positive COVID-19 test during the period March-31 May 2020 across 160 VA facilities, marked heterogeneity in patient volume, admissions to the hospital and to the ICU, mechanical ventilation and 45-day, all-cause mortality were observed across VA facilities. However, after adjustment for differences in patient characteristics, mortality was similar across VA facilities nationwide.

\section{Author affiliations}

${ }^{1}$ Department of Veterans Affairs (VA) Health Services Research and Development (HSR\&D) Precision Monitoring to Transform Care (PRISM) Quality Enhancement

Research Initiative (QUERI), Indianapolis, Indiana, USA

${ }^{2}$ VA HSR\&D Center for Health Information and Communication (CHIC), Richard L. Roudebush VA Medical Center, Indianapolis, Indiana, USA

${ }^{3}$ Medicine Service, Richard L. Roudebush VA Medical Center, Indianapolis, Indiana, USA

${ }^{4}$ Internal Medicine, Indiana University School of Medicine, Indianapolis, Indiana, USA

${ }^{5}$ Health Services Research, Regentrief Institute, Indianapolis, Indiana, USA

${ }^{6}$ Biostatistics, Indiana University School of Medicine, Indianapolis, Indiana, USA

${ }^{7}$ Department of General Internal Medicine, San Francisco VA Medical Center, San Francisco, California, USA

${ }^{8}$ San Francisco VA Medical Center, Department of Veterans Affairs, San Francisco, California, USA

${ }^{9}$ Department of Biostatistics, College of Public Health, University of Nebraska Medical Center, Omaha, Nebraska, USA

${ }^{10}$ Department of Pharmacy Practice, Purdue University College of Pharmacy, West Lafayette, Indiana, USA

${ }^{11}$ Emergency Medicine, Indiana University School of Medicine, Indianapolis, Indiana, USA

${ }^{12}$ School of Nursing, Purdue University System, West Lafayette, Indiana, USA

Contributors All authors participated in the revision of the manuscript and read and approved the final manuscript. DMB: obtained funding, was responsible for the design and conduct of the study including oversight of data collection and data analysis, interpretation of the results and drafting and revising the manuscript. LJM: obtained the data, developed the algorithms used to identify COVID-19 positive patients and ascertain mortality status and was instrumental in the conduct of the chart review validation, data analysis, interpretation of the results and development of the manuscript. AJP: conducted the data analysis and was instrumental in the conduct of the chart review validation, interpretation of the results and development of the manuscript. SK, YZ, AJZ, AD, RL, DS and GA: were instrumental in the development of the analysis plan, conduct of the data analysis, interpretation of the results and development of the manuscript. JM, CA and AS: provided regulatory and administrative oversight, conducted the chart review validation and contributed to the interpretation of results and revision of the manuscript. DMB and AJP had full access to all the data in the study and take responsibility for the integrity of the data and the accuracy of the data analysis.

Funding This work was supported by the US Department of Veterans Affairs (VA) Health Services Research \& Development Service, Precision Monitoring to Transform Care Quality Enhancement Research Initiative (QUE 15-280). The contents do not represent the views of the US Department of Veterans Affairs or the US Government. This study used data from the VA COVID-19 Shared Data Resource.

Disclaimer The funding agency had no role in the design or conduct of the study; collection, management, analysis, or interpretation of the data; preparation, review or approval of the manuscript; or the decision to submit the manuscript for publication.

\section{Competing interests None declared.}

Patient consent for publication Not required.

Ethics approval This observational cohort study received human subjects (Indiana University Institutional Review Board) and VA Research and Development committee (Richard L. Roudebush VA Medical Center) approvals. 
Provenance and peer review Not commissioned; externally peer reviewed.

Data availability statement No data are available. These data must remain on VA servers and are therefore not available to be accessed directly. In the interest of data transparency, investigators interested in working with the data are encouraged to contact the corresponding author.

Supplemental material This content has been supplied by the author(s). It has not been vetted by BMJ Publishing Group Limited (BMJ) and may not have been peer-reviewed. Any opinions or recommendations discussed are solely those of the author(s) and are not endorsed by BMJ. BMJ disclaims all liability and responsibility arising from any reliance placed on the content. Where the content includes any translated material, BMJ does not warrant the accuracy and reliability of the translations (including but not limited to local regulations, clinical guidelines, terminology, drug names and drug dosages), and is not responsible for any error and/or omissions arising from translation and adaptation or otherwise.

Open access This is an open access article distributed in accordance with the Creative Commons Attribution Non Commercial (CC BY-NC 4.0) license, which permits others to distribute, remix, adapt, build upon this work non-commercially, and license their derivative works on different terms, provided the original work is properly cited, appropriate credit is given, any changes made indicated, and the use is non-commercial. See: http://creativecommons.org/licenses/by-nc/4.0/.

ORCID iD

Dawn M Bravata http://orcid.org/0000-0002-3048-2536

\section{REFERENCES}

1 Richardson S, Hirsch JS, Narasimhan M, et al. Presenting characteristics, comorbidities, and outcomes among 5700 patients hospitalized with COVID-19 in the new York City area. JAMA 2020;323:2052-9.

2 Grasselli G, Zangrillo A, Zanella A, et al. Baseline characteristics and outcomes of 1591 patients infected with SARS-CoV-2 admitted to ICUs of the Lombardy region, Italy. JAMA 2020;323:1574-81.

3 Young BE, Ong SWX, Kalimuddin S, et al. Epidemiologic features and clinical course of patients infected with SARS-CoV-2 in Singapore. JAMA 2020;323:1488-94.

$4 \mathrm{Wu}$ Z, McGoogan JM. Characteristics of and important lessons from the coronavirus disease 2019 (COVID-19) outbreak in China:summary of a report of 72314 cases from the Chinese center for disease control and prevention. JAMA 2020.

5 Dennis JM, McGovern AP, Vollmer SJ. Improving survival of critical care patients with coronavirus disease 2019 in England: a national cohort study, March to June 2020. Crit Care Med 2020.

6 Petrilli CM, Jones SA, Yang J, et al. Factors associated with hospital admission and critical illness among 5279 people with coronavirus disease 2019 in New York City: prospective cohort study. BMJ 2020;369:m1966.

7 Bui DP, See I, Hesse EM, et al. Association Between CMS Quality Ratings and COVID-19 Outbreaks in Nursing Homes - West Virginia, March 17-June 11, 2020. MMWR Morb Mortal Wkly Rep 2020;69:1300-4.

8 Abrams HR, Loomer L, Gandhi A, et al. Characteristics of U.S. nursing homes with COVID-19 cases. J Am Geriatr Soc 2020;68:1653-6.

9 National Center for Veterans Analysis and Statistics (NCVAS). VA utilization profile: FY 2017. US Department of Veterans Affairs OoDGaA, 2020.

10 U.S. Department of Veterans Affairs. Veterans health administration 2019. Available: https://www.va.gov/health/findcare.asp\#: :text=
The $\% 20$ Veterans $\% 20$ Health\%20Administration\%20is,9\%20million\% 20enrolled\%20Veterans\%20each [Accessed 9 Jul 2020].

11 Development VHSR. VA informatics and computing infrastructure (VINCI), 2008. Available: https://www.hsrd.research.va.gov/for researchers/vinci/default.cfm [Accessed 10 Dec 2020].

12 Borzecki AM, Wong AT, Hickey EC, et al. Can we use automated data to assess quality of hypertension care? Am J Manag Care 2004;10:473-9.

13 Sohn M-W, Arnold N, Maynard C, et al. Accuracy and completeness of mortality data in the Department of Veterans Affairs. Popul Health Metr 2006;4:2.

14 Veterans Health Administration OoESaPO. Veterans health administration (VHA) facility complexity model, 2017.

15 Fonarow GC, Pan W, Saver JL, et al. Comparison of 30-day mortality models for profiling hospital performance in acute ischemic stroke with vs without adjustment for stroke severity. JAMA 2012;308:257-64.

16 Pan A, Liu L, Wang C, et al. Association of public health interventions with the epidemiology of the COVID-19 outbreak in Wuhan, China. JAMA 2020;323:1915-9.

17 Wadhera RK, Wadhera P, Gaba P, et al. Variation in COVID-19 hospitalizations and deaths across New York City boroughs. JAMA 2020;323:2192-5.

18 Williamson EJ, Walker AJ, Bhaskaran K, et al. Factors associated with COVID-19-related death using OpenSAFELY. Nature 2020;584:430-6.

19 Palaiodimos L, Kokkinidis DG, Li W, et al. Severe obesity, increasing age and male sex are independently associated with worse inhospital outcomes, and higher in-hospital mortality, in a cohort of patients with COVID-19 in the Bronx, New York. Metabolism 2020;108:154262.

20 Khalili M, Karamouzian M, Nasiri N, et al. Epidemiological characteristics of COVID-19: a systematic review and meta-analysis. Epidemiol Infect 2020;148:e130.

21 Thompson JV, Meghani NJ, Powell BM, et al. Patient characteristics and predictors of mortality in 470 adults admitted to a district general Hospital in England with Covid-19. Epidemiol Infect 2020;148:e285.

22 Parcha V, Malla G, Suri SS, et al. Geographic variation in racial disparities in health and coronavirus Disease-2019 (COVID-19) mortality. Mayo Clin Proc Innov Qual Outcomes 2020;4:703-16.

23 Pollán M, Pérez-Gómez B, Pastor-Barriuso R, et al. Prevalence of SARS-CoV-2 in Spain (ENE-COVID): a nationwide, population-based seroepidemiological study. Lancet 2020;396:535-44.

24 Karim SA, Chen H-F. Deaths from COVID-19 in rural, Micropolitan, and metropolitan areas: a County-Level comparison. J Rural Health 2021;37:124-32.

25 Guan W-J, Ni Z-Y, Hu Y, et al. Clinical characteristics of coronavirus disease 2019 in China. N Engl J Med 2020;382:1708-20.

26 Rossato M, Russo L, Mazzocut S, et al. Current smoking is not associated with COVID-19. Eur Respir J 2020;55:2001290.

27 Tsigaris P, Teixeira da Silva JA. Smoking prevalence and COVID-19 in Europe. Nicotine Tob Res 2020;22:1646-9.

28 Sifat $\mathrm{AE}$, Nozohouri S, Villalba $\mathrm{H}$, et al. The role of smoking and nicotine in the transmission and pathogenesis of COVID-19. $J$ Pharmacol Exp Ther 2020;375:498-509.

29 Zhao Q, Meng M, Kumar R, et al. The impact of COPD and smoking history on the severity of COVID-19: a systemic review and metaanalysis. J Med Virol 2020;92:1915-21.

30 Myers LC, Parodi SM, Escobar GJ, et al. Characteristics of hospitalized adults with COVID-19 in an integrated health care system in California. JAMA 2020;323:2195-8.

31 Shulkin DJ. Why Va health care is different. Fed Pract 2016;33:9-11.

32 Baum A, Schwartz MD. Admissions to Veterans Affairs hospitals for emergency conditions during the COVID-19 pandemic. JAMA 2020;324:96-9. 